\title{
Rates of Solubilization and Biodegradation of PAH Compounds in Porous Media
}

(Keywords: Oil-water interfaces, 159; biodegradation, 26; contaminant transpor, 48)

\author{
Richard G. Luthy \\ Department of Civil Engineering \\ Carnegie Mellon University \\ $D E-F G 22-90 P C 90303$
}

$\mathrm{DOE} / \mathrm{PC} / 90303-\mathrm{T} 2$

DE92 011417

\section{Objectives}

Microbial degradation of hydrophobic organic compounds in soils and aquifer media is dependent on rates of desorption of these compounds from solids and rates of solubilization from residual nonaqueous phase liquids (NAPLs). The coupled processes involving microbial degradation and hydrophobic compound availability are not well understood. The proposed research effor explores cerrain physicochemical phenomena that may have a significant affect on the rate of microbial degradation of hydrophobic organic compounds in porous media. The investigation will examine rates of biomineralization of polycyclic aromatic hydrocarbon (PAH) compounds that are leached from a residual saturation of coal tar. Batch and continuously-stirred reactor studies will be used to measure solute equilibrium concentrations and rates of solubilization of PAH compounds from coal tar imbibed into microporous silica media. These rates will be compared with rates of mineralization of ${ }^{14} \mathrm{C}$-labeled compounds in similar systems inoculated with a culture of PAH degrading microorganisms. Column experiments will also be conducted 10 assess the rates of solubilization and mass transfer coefficients from coal tar enirapped in a sandy aquifer material by capillary forces.

The overall goal of this research is to develop understanding of physicochemical mechanisms that may control rates of bioremediation. The potential for equilibrium or rate-limited mass exchange of PAH compounds to limit biodegradation rates will be explored. Mathematical models for PAH equilibrium concentrations and solubilization rates will be developed. The results from these experimental studies will be used to test the hypothesis that biodegradation of coal tar solutes may be limited by rates of solubilization. The central theme is to understand the concept of "bioavailability" and its relation to potential rates and endpoints for microbial remediation.

\section{Backgruund}

Bioremediation of organic-contaminated soils and sedimenis may be a cost effective technology for environmental cleanup and aquifer restoration. However, not much is known about the physicochemical

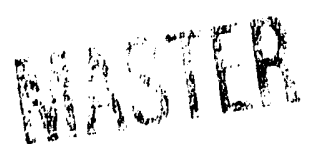


mechanisms that may control the rate of bioremediation for environmental samples. This is particularly the case for hydrophobic organic solutes that may be adsorbed onto soil, or that may exist as a nonaqueous phase liquid. Understanding rate-controlling processes in bioremediation is complicated by the interplay between physicochemical phenomena goveming phase partitioning, and interfacial processes affecting both the microorganism and the organic compounds.

Hydrophobic organic col.upounds (HOCs) strongly interact with soil and sediment material (Karickhoff, 1984; Huling and Weaver, 1991), and consequently the effectiveness of microbial treatment can be affected by the processes that control solute accessibility to microorganisms and phase partitioning between solid or NAPL and the aqueous phase. While much has been learned in recent years individually on microbial transformation of HOCs in soil and in the subsurface, and on the processes of NAPL contaminant behavior in soil and aquifer materials, there is comparatively little knowledge on the combined effects of solubilization and microbial degradation on organic compound transformation and fare (Alvarez et al, 1989; Mihelcic and Luthy, 1990).

\section{HOC Solubilization from NAPL}

Aqueous phase concentrations of PAH compounds dissolving from a NAPL source are potentially limited by chemical and physical phenomena. Even under conditions where the aqueous phase is in equilibrium with the concentration of a species in a complex NAPL, such as a coal tar, concentrations of individual components may be low, due to the small mole fraction of each constituent in the mixture. Over the course of time, the most soluble components are prefereitially leached out of the organic phase, further reducing their mole fraction in the NAPL and, hence, reducing the associated aqueous phase concentrations. Several researchers have documented this phenomenon (van der Waarden, 1971; Fried et al., 1979; Borden and Kao, 1989; Razakarisoa et al., 1989; Geller, 1990). Geller (1990) measured the equilibrium dissolution rates of a mixture of benzene $(50 \%)$ and toluene $(50 \%)$ entrapped in a glass bead media. Initially, the aqueous phase concentration of benzene was much higher than that of toluene, due to its higher solubility in water. Over time however, as the source of benzene was depleted and the mole fraction of toluene increased, the concentration of benzene decreased and the concentration of toluene in the aqueous phase increased in proportion to the changes in their respective mole fractions. Similar results for more complex mixtures have been shown by Razakarisoa el al. (1989), Borden and Kao (1989) and Parker et al. (1990) who have measured aqueous phase effluent concentrations of hydrocarbon species from packed columns containing residual saturations of complex hydrocarbon mixtures. In each

of these studies, it was found that aqueous phase $c$.centrations decrease with time as the mole fraction in the NAPL is decreased. Razakarisoa et al. (1989) observed that rates of impoverishment of individual species from complex NAPL mixtures are a function of both equilibrium solubility of the pure species in water and the mole fraction of the species in the NAPL mixture. Experimental results for the rate of dissolution of PAH const: ients from coal tar have not been published. 
Changes in aqueous phase concentrations as solubilization of a NAPL occurs are largely controlled by the thermodynamic equilibria between phases. However, aqueous phase concentrations are sometimes found to be even lower than predicted by equilibrium considerations due to physical limitations of the rate of exchange of species between phases. Geller (1990) found that if the two-component NAPL. dissolution experiments were continued for extended periods of time, the total mass of NAPL entrapped within the porous medium was reduced and equilibrium concentrations were no longer observed. Under these conditions, equilibrium descriptions of the solubilization process are no longer valid. Miller et al. (1990) and Powers et al. (in prep.(a)) have investigated factors limiting NAPL-water mass transfer rates in porous media. In each of these cases, pure phase NAPLs were entrapped in a packed column. Miller et al. (1990) investigated dissolution rates of toluene entrapped in a bed of uniform sized glass beads. It was observed that effuent concentrations decrease with increasing aqueous phase velocities due to the limiting contact time between phases. Powers et al. (in prep.(a)) also observed this phenomenon, but found that several other system parameters also limit interphase mass transfer rates. In this series of experiments, styrene or trichloroethylene (TCE) was entrapped in a sandy porous matrix. The manner in which the NAPL was entapped was designed to replicate the capillary action dictating migration of organic phases through an aquifer system. Their results indicate that characteristics of the porous matrix are also critical parameters controlling dissolution rates. In graded media, it was found that a majority of the NAPL was distributed as large, amorphous ganglia occupying several adjacent pores. NAPL. distributed in this manner would be expected to have a limited interfacial area across which mass transfer could occur. Effluent concentrations in the graded sands were found to be less than in systems comprised of a uniform matrix. Over time, these researchers have noted that this effect is enhanced (Powers et al., in prep.(b)). Mass transfer rates severely limit aqueous phase concentrations as the total mass and interfacial arca across which mass transfer can occur is reduced.

The significance of mass transfer rate limitations has been explored by Powers et al. (1991). Over the course of a pump-and-treat remediation effon. concentrations in the aqueous phase were predicted to te reduced substantially, decreasing the rate at which the contaminant was removed from the system and increasing the total remediation time. Similar limitations may occur in bioremediation strategies. Available soluble carbon source concentrations may become limiting either due to a reduction in the mole fraction of the species in the NAPL. or due to limited NAPL-water surface area for mass transfer.

\section{HOC Availability and Biodegradation}

There is little specific information on the manner in which solubilization of polycyclic aromatic hydrocarbon (PAH) compounds from NAPL effects the rate of microbial degradation. However, inferences may be made from the limited information on microbial degradation of PAH and related compounds as solid substrates or as solutes sorbed onto soil. Although substrate sorption may be stimulatory if an otherwise soluble compound is toxic to microorganisms, often sorption of hydrophobic 
solutes has been suggested as decreasing bioconversion rates. While the specific impact of sorption on microbial degradation of organic compounds in soils depends on various factors, some of the reasons offered to explain these effects include (Thomas and Ward, 1989; Stucki and Alexander, 1987):

- Soil microorganisms are more effective in utilizing soluble substrates,

- Sorption may decrease aqueous concentration and limit high potential rates, and

- Sorption may lower substrate concentration to less than threshold values for biodegradation.

These arguments indicate that phase partitioning or sorption of hydrophobic organic substrates can hinder microbial activity in soils or sediments. It appears that this is the case for microbial degradation of PAH compounds in tar or oil, or soil/sediment systems. Some examples for PAH compounds that suggest that decreased solubility, and/or non-aqueous phase partitioning and sorption processes, are restrictive towards microbial degradation are:

i. Naphthalene, Biphenyl and Phenanthrene (Wodzinski and Bertolini, 1972; Wodzinski and Coyle, 1974). The evidence indicates that bacteria utilize naphthalene, biphenyl and phenanthrene as dissolved solutes with the rate being independent of the total amount of solid-phase PAH hydrocarbon.

ii. Phenanthrene (Stucki and Alexander, 1987). The dissolution rate of phenanthrene may limit the rate of biodegradation.

iii. PAH in water or soil (Gauger et al. 1989). Bioavailability may be the chief factor limiting the rate and extent of PAH degradation.

iv. Naphthalene in soil/water suspension (Mihelcic and Luthy, 1990). The rate of degradation may be modeled by assuming that solid-associated substrate is inaccessible to microorganisms. Microbial degradation creates a concentration gradient for sorbed solute to desorb and diffuse through pore water to the bulk liquid.

Investigations with other organic compounds and soils or clays also suggest that sorption of organic solute either slows biodegradation or renders the compound poorly accessible to microorganisms (Ogram et al., 1985: Rijnaans et al., 1990).

\section{Observations on Bioremediation of PAH in Soil with Coal Tar or Oil}

Observations on bioremediation of soils contaminated with coal tar suggest that PAH phase partitioning and/or sorption may control the rate and extent of the microbial degradation processes. Work with soils having PAH-containing coal tar at former manufactured gas plant sites indicates that PAH dissolution from coal tar may be a limiting factor in achieving bioremediation of such sites (Smith et al., 1989; Gauger et al.. 1989; Neuhauser, 1989). It has been demonstrated in controlled aerobic microcosm studies with acclimated organisms that PAH solutes from coal tar can be degraded readily as aqueousphase compounds. However, biodegradation for removal of PAH from the soil mass approaches a 
limiting value, after which little change in total PAH concentration is often apparent.

The consensus from various investigations with PAH compounds and soils is that 2- through 5-ring PAH compounds can be biodegraded in liquid cultures given appropriate microbial populations and environmental conditions, although higher-ring PAH compounds are probably not capable of providing the sole carbon source owing to their limited solubility, and those compounds are not degraded as effectively as lower-ring PAH compounds. An examination of PAH biodegradation from manufactured gas plant soil treatment systems demonstrates a pattem different from that for aqueous systems. The trends for soil treatment in laboratory systems under ideal conditions indicate: (i) removal of 2-and 3-ring PAHs over the first six to eight weeks after which little additional removal is observed, and (ii) little or no removal of the 4-, 5- and 6-ring PAHs. In the past, some researchers have atributed these differinces to the higher molecular weight PAHs being more recalcitrant to biodegradation than the lower molecular weight PAHs. However, more recent studies suggest that the lower removal rates observed for higher molecular weight PAHs reflect their low concentrations and release to the aqueous phase. Several expcrimental studies have been conducted to investigate the biological treatment of 2-through 6-ring PAHs present in liquid cultures and solid matrices associated with manufactured gas plant site soils (Smith and Weightman, 1988; Sherman et al., 1988). The results of these efforis have indicated that a range of 2-through 6-ring PAHs may biodegrade when present in aqueous solution; however, removal from a solid matrix is less predictable and. generally, much less efficient. On the basis of such data, it is hypothesized that soil-waste matrix effects are preventing the release of the PAHs into the aqueous phase where they may undergo biodegradation, i.e., it is mass transfer limitations associated with the release of the contaminants from the soil-waste matrix that limit the rate of removal of PAHs from the soil, rather than the explicit aqueous-phase biodegradation kinetics.

Nakles et al. (1991) obtained a similar conclusion from laboratory biodegradation studies with pan (unmixed) and slurry (mixed) systems. PAH contamination may exist in several forms in soils or aquifer media at former manufactured gas plant sites or wood preserving facilities: (i) PAH sorbed onto nonporous matter, e.g., sand, (ii) PAH sorbed onto porous aggregates, and (iii) PAH residing in oils or tars as NAPLs. It is suggested from their qualitative interpretations that rates of desorption govern degradation from nonporous matuer (e.g., sand), rates of retarded diffusion govem degradation from fine aggregates, and rates of dissolution govem degradation of PAH from NAPL oils or tars. Their results for studies with two soils are shown in Figure 1, and were explained as follows:

Soil D:

approximately $25 \%$ of this soil is comprised of panicies less than 75 microns. The PAH exist as sorbed solutes. The pan and slurry reactors show different results because the rate of bioremediation is governed by diffusion from fines. The slurry reactor helps promote disaggregation of larger aggregates, while providing no limitations to nutrient or oxygen mass transfer. Bioremediation in the slurry reactor was very effertive in a few weeks. 
Soil F:

this soil contains PAH compounds in a NAPL. The pan and slurry reactors approach the same level of removal, although the rate of degradation is dependent on reactor configuration. The bioremediation process appears dependent on the extent to which PAH may be solubilized from the NAPL; residual PAH after microbial treatment remains trapped within the NAPL and may be slowly solubilized.

\section{Bioremediation of Soil D}

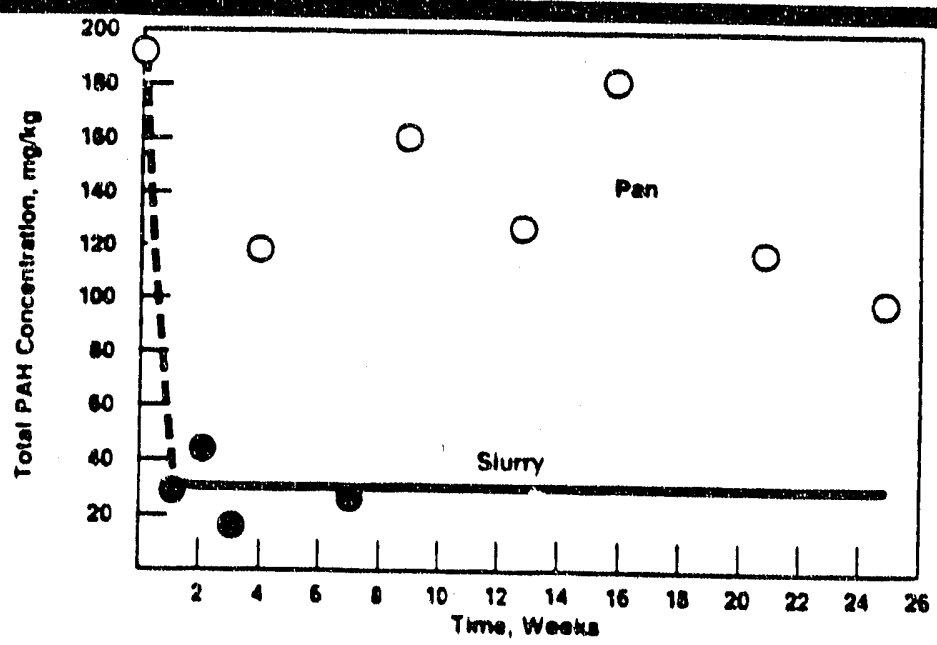

Bioremediation of Soil F

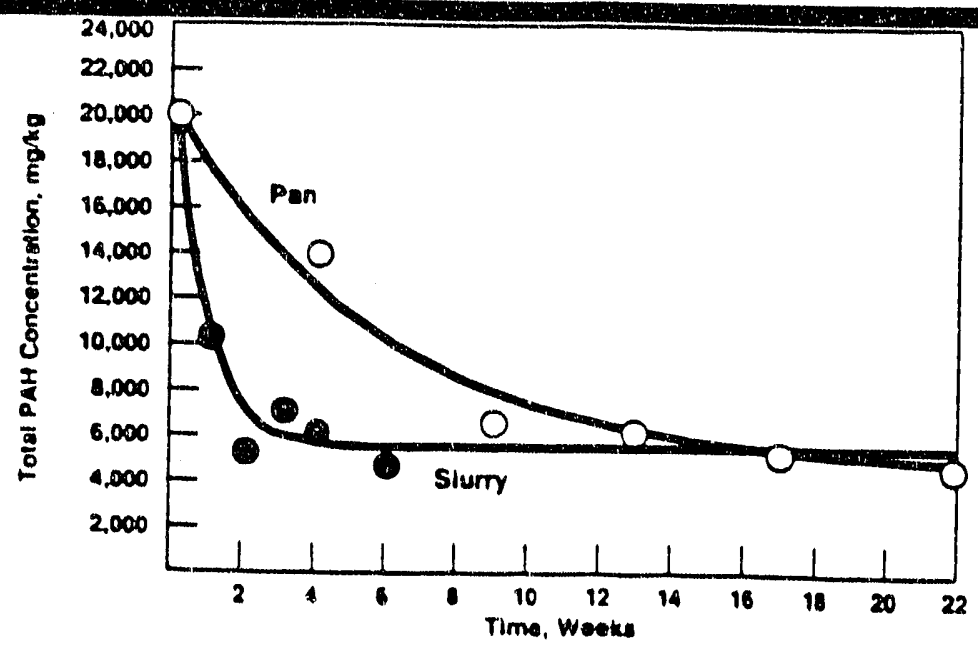

Figure 1: Bioremediation of PAH in two soils (Nakles et al., 1991). Soil D contains PAH as sorbed solutes; Soil F contains PAH compounds in a NAPL for which the level of removal is much less efficient. 
These qualitative interpretations indicate that mass transport limitations are important in bioremediation of PAH compounds in pomus media, and that substantial amounts of PAH may be trapped within NAPL and slowly be released. Data were not available to quantify the physicochemical rates that were apparently limiting the biodegradation rates in this study. The research plan discussed below will investigate the rates of solubilization of PAH constituents from coal tar and rates of biomineralization in order develop a more complete picture of the extent that surface solubilization phenomena govem bioremediation of residual NAPL material in porous media.

\section{Research Tasks}

The above has shown that microbial degradation of PAH compounds leached from NAPLs entrapped in subsurface media appears to be dependent on rates of solubilization from NAPLs. Such processes are not well understood, however, leading to the need for tefinement and verification of conccptual models for these processes. Improved mechanistic understanding of the coupled processes involving solubilization and biodegradation of PAH from N.APLS in porous media will allow development of better predictive techniques for environmental restoration.

An appropriate research plan for better understanding the rate-controlling processes and for evaluating limits to biodegradation will involve quantification of two mechanisms. Rates of biomineralization and solubilization will be measured independently and jointly in a model porous medium. These experiments will provide a means of assessing the effect of solubilization rates on biodegradation processes. In addition, rates of solubilization will be measured in column experiments to evaluate the significance of rate limited mass exchange processes in subsurface bioremediation efforts. The specific experiments and tasks that will be conducted to meet these goals are:

i. control studies in batch and flow-through reactors, devoid of microbial activity, to evaluate conditions leading to equilibrium concentrations versus rate limited solubilization of constituents from residual coal tar imbibed into porous silica media,

ii. measurement of the biodegradation of several constituents from residual NAPL imbibed into porous silica media in analogous reactor systems as the control studies,

iii. column studies to measure the solubilization rates of organic constituents from coal tar entrapped in a packed bed of sandy media in a manner which is representative of a homogeneous aquifer system.

iv. modeling PAH equilibrium concentration and rate of mass exchange of PAH from coal tar NAPL, and

v. comparisc. If rates of biodegradation with mass transfer rates in mixed-and packed-bed systems to determine under what conditions the rate-limiting step is biokinetic or physicochemical.

The coal tar which will be used in these studies was pumped from a remediation recovery well in 
Stroudsburg, PA at the site of a former manufactured gas plant. This location was the nation's first Emergency Superfund site, for which some free-product coal tar was pumped from the surface and slurry walls were constructed to restrict groundwater flow through the site (Villaume, 1985). It is estimated that this site may be similar to more than one thousand locations of former manufactured gas plants where the majority of the original coal tar mass disposed to the subsurface is present at residual saturation following recovery of any free-phase material. The coal tar is slightly more viscous than water and is comprised of a variety of aromatic hydrocartons and PAH compounds, e.g., percent by weight, $2.2 \%$ naphthalene, $3.8 \% 1$-methyl naphthalene, $1.5 \%$ acenaphthene, $2.1 \%$ phenanthrene, $0.6 \%$ anthracene, etc. (Peters and Luthy, 1991). In contrast to other NAPLs. coal tar may be an exception where the wetting phase on solids is the NAPL not water, i.e., the coal tar contact angle is greater than 90 degrees (Huling and Weaver, 1991).

Solubilization of PAH from Coal Tar NAPL

\section{Methodology}

Equilibrium and rate limited solubilization of organic solutes from coal tar will be measured in batch and continuously-stirred reactors. These cells will be designed to mimic the hydrodynamics of the biometers employed in the biomineralization studies. Coal tar will be imbibed into porous silicis beads to provide about $20 \%$ residual saturation. Equilibrium and rate-limited mass exchange will be achieved by varying aqueous phase flow velocities, mass of porous beads, and stirring rate. The specific protocol used in these experiments will consist of the following:

i. A specified mass of porous silica containing a coal tar will be placed in a closed batch system and in a small, headspace-free, continuously-stirred reactor,

ii. Water will be pumped through the cell at a constani flow rate while stirring the silica media,

iii. Samples from the batch tests and efnuent samples from the reactor cell will be collected and analyzed by chromatographic and radiolabeled techniques for various slightly soluble species (e.g., benzene, toluene, naphthalene).

iv. Initial dissolution rates will be assessed with the continuously-stirred reactor by considering several aqueous phase velocities.

$v$. Long-term changes in aqueous phase concentrations due to depletion of the contaminant source will be measured for a sub-set of tests with the continuously-stirred reactors,

vi. Results from the batch tests will be compared with predicted equilibrium concentration from solubility theory,

vii. Results of the rate-limited solubilization studies will be expressed as mass transfer rates as a function of aqueous phase velocity.

viii. The minimum asymptotic mass transfer coefficient will be determined at low aqueous phase velocities,

ix. The rates of solubilization will be compared to the rates of biodegradation measured in analogous biometer tests to assess the effect of mass transfer processes on biodegradation rates. 


\section{Biodegradation of FAH fmom Coal Tar}

The experimental protocols for enumerating PAH-degrading rricroorganisms, and using biometer batch reactors with radiolabled PAH compounds, have been developed in previous experiments on microbial minerelization of phenanthrene in soil (Laha and Luthy, 1991). This protocol has been adapted for this study. Experiments measuring biodegradation of coal tar constituents will consist of the following:

i. Coal tar composition will be determined for a sample by GC/MS techniques for various representative aromatic compounds ranging from one-ring (t.g., benzene and toluene) to four- (e.g.. pyrene) and five-ring (e.g.. benzo(a)pyrene) constituents,

ii. A selected ${ }^{14} \mathrm{C}$-labeled PAH compound will be added to coal tar, e.g. ${ }^{14} \mathrm{C}$-naphthalene. Various such individual ${ }^{14} \mathrm{C}$-labeled coal tar samples will be prepared,

iii. The labeled coal tar will be imbibed into microporous silica beads (e.g., sodium silicate, 236 micron diameter) 10 provide about $20 \%$ residual saturation,

iv. Several grams of coal-tar-containing porous silica beads will be placed in a biometer flask with side am containing $\mathrm{NaOH}$, followed by addition of nutrient solution, inoculation with a culture of PAH-degrading microorganisms, addition of oxygen and sealing of the flask,

$v$. Placing the flask on a timed magnetic stirrer, periodically sampling and replacing the $\mathrm{NaOH}$ solution in the side arm, adding oxygen, and counting for ${ }^{14} \mathrm{C}-\mathrm{CO}_{2}$,

vi. Expressing the results as percent PAH mineralized versus time; and at the conclusion of the expetiment sampling the coal-tar-coated silica, combusting in a biological oxidizer and performing a mass balance on radiolabeled $\mathrm{PAH}$.

vii. Such studies will be performed for a range of coal tar aromatic constitutes from benzene and toluene, which are relatively soluble, to higher ring compounds representing decreased solubility.

Figure 2 shows the results of a preliminary test using the procedures outlined above for naphthalene mine:ralization from coal tar. This screening test was conducted during September and October, 1991, for purposes of demonstrating the basic concepts. In these tests $1.0 \mathrm{ml}$ of coal tar was applied to $5 \mathrm{~g}$ porous sodium silicate (236 micron diamcter, 174 Angstrom pore diameter, PQ Corporation, Conschohaclien, $\mathrm{F}^{\prime} \mathrm{A}$ ) and placed in $50 \mathrm{ml}$ nutrient solution. These results show an initial rapid mineralization of naphthalene, during which about 10\% was mineralized in about one to two weeks. Following this high initial rate, there was much slower rate of mineraliza ion of about $1-2 \%$ per week. Additional screening tests will be performed with $\mathrm{C}_{4}$ - and $\mathrm{C}_{18}$-bonded porous sodium silicate of similar size to evaluate the extent that surface-modified porous media may prevent the formation of any organic phase surface films in long-term tests. 


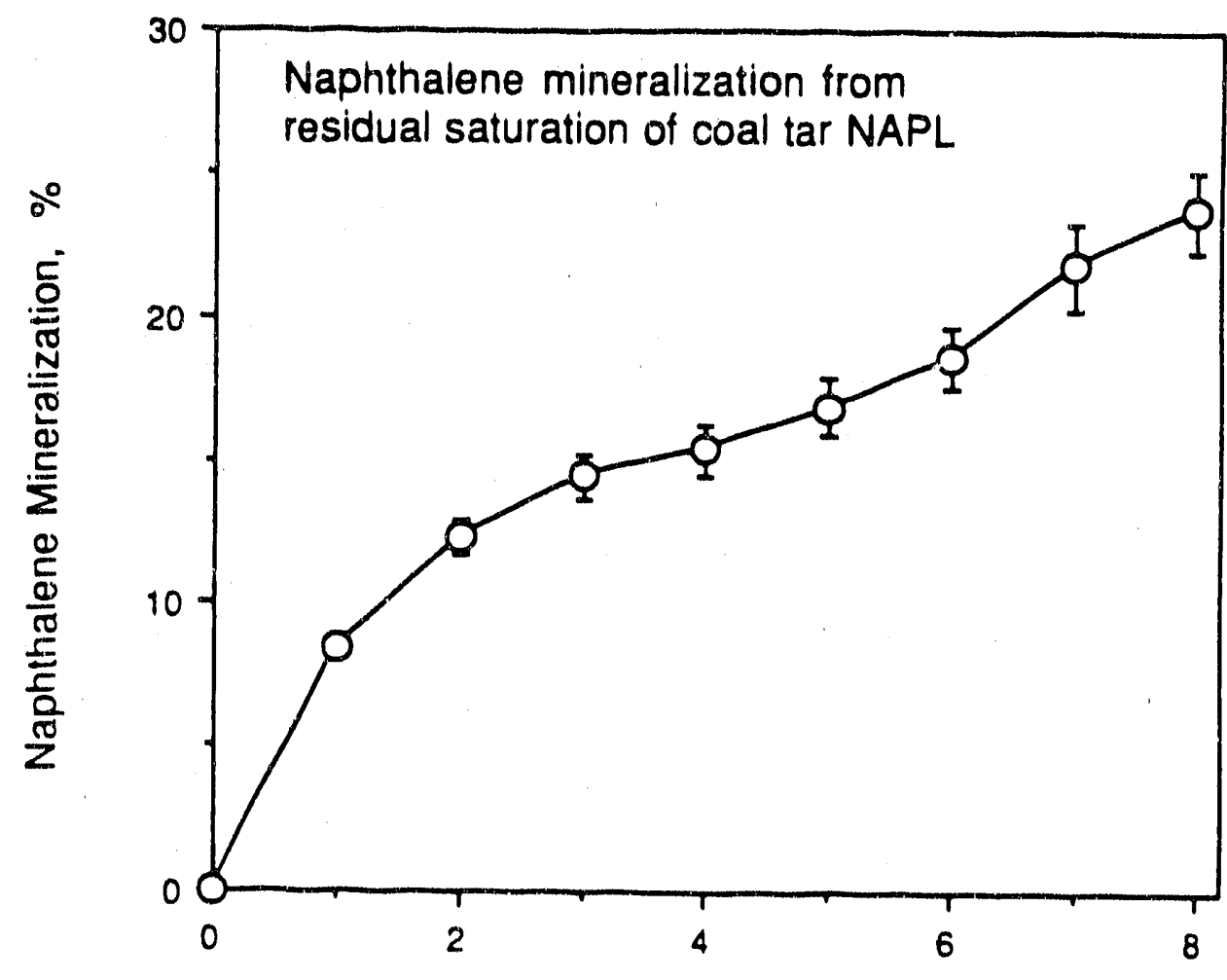

Time, weeks

Figure 2: Results of a preliminary test to evaluate microbial mineralization of naphthalene from coal tar NAPL in porous sodium silicate.

It is believed that the higher initial biodegradation rate observed in Figure 2 corresponds to mineralization of naphthalene not substantially depleted from the coal tar by solubilization processes. Following this initial period, the slower rate of mineralization may result from mass-transfer-limited solubilization from the coal tar. This issue will $b e$ assessed in solubilization tests.

\section{Solubilization of PAH from Coal Tar NAPL in Soil Columns}

Column studies will be used to measure NAPL dissolution rates from coal tars entrapped in a graded, sandy medium. The results of this investigation should further identify the potential for mass transfer rates to limit bioremediation processes. The general procedure used for these experiments will follow those developed by Powers et al. (in prep.(a)); a schematic of the experimental cunfiguration is shown in Figure 3. The overall approach is summarized here:

i. Uniformly pack a shon laboratory column with dry sand, saturate with de-aired water,

ii. Slowly pump NAPL into the column until approximately $75 \%$ of the r re space contains 
NAPL. Displace NAPL with a water flood until a residual saturation is achieved,

iii. Pump water through the colurnn until psuedo-steady-state concentrations are achieved. Analyze effluent concentrations by chromatographic or radiolabeled analytical techniques. Repeat for several aqueous phase velocities,

iv. Continue a sub-set of the experiments over time to observe changing effluent concentrations as contaminant source is depleted.

$\checkmark$. Calculate lumped mass transfer coefficients as a function of aqueous phase velocities.

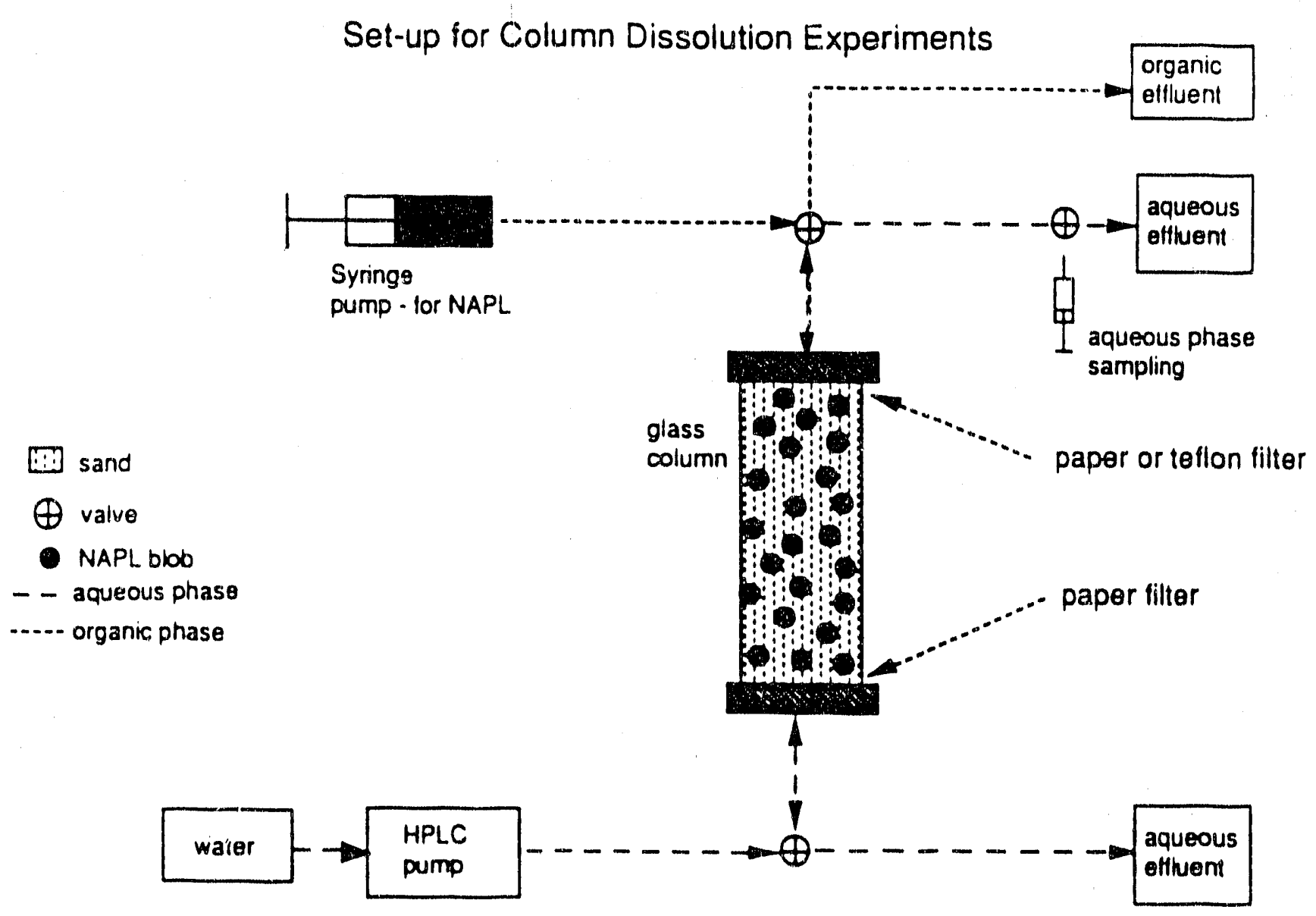

Figure 3: Experimental configuration for NAPL dissolution in column tests (Powers et al., in prep.(a)). 


\section{Modeling Techniques}

\section{Modeling Equilibrium Concentration of PAH from Coal Tar NAPL}

The equilibrium concentration of PAHs leached from coal tar NAPL will be measured using radiolabled techniques in batch experiments. Measured equilibrium concentration of coal tar PAH constituents will be compared with an equilibrium dissolution model as described below.

The equilibrium dissolution of an organic non-electrolyte from a liquid mixture into water occurs when the chemical potential of the solute is equal in the two liquids. Utilizing the same reference state in both phases, and assuming that the molar volume of the solute is the same in both phases, then the activity of a species is the same in both phases.

$$
\gamma_{1}^{w} \chi_{1}^{w}=\gamma_{1}^{N A P L} \chi_{i}^{N A P L}
$$

where $i=$ PAH solute, $\gamma=$ solute activity coefficient in water $(w)$ and NAPL, and $\chi=$ solute mole fraction in each phase. The coal tar NAPL is not a pure liquid, and the PAH solute solubility may be expressed generally as

$$
\chi_{1}^{w}=\gamma_{1}^{N A P L} \chi_{i}^{N A P L} \chi_{i}^{w^{*}}
$$

where $\quad \chi_{1}^{\omega^{*}}=$ pure PAH liquid compound mole fraction aqueous solubility. Thus the solubility of the PAH solute can be expressed as a function of the pure liquid solubility, the mole fraction of the compound in the NAPL mixture, and the non-ideal interactions, i.e., the activity coefficient of the PAH compound in the mixture. The pure liquid aqueous solubility must be determined from thermodynamic considerations, as the coal tar mixture of PAH is liquid but the individual pure compounds for 2-ring and higher molecular weight PAH are solids. The term $\chi_{1}^{\omega^{*}}$ for solids must be determined from the difference in the free energy of a solute molecule in its pure form and the energy it would have as a pure liquid at the same ternperature and pressure, termed the hypothetical subcoded liquid state (Tsonopoulos and Prausnitz, 1971: Yalkowsky and Valvani, 1979; Campbell and Luthy, 1985). It is necessary to account for the energy required to melt the solid at the temperature and pressure of the system. With neglection of the minor terms relating to change in heat capacity from the solid to the liquid, the hypothetical pure liquid solubility is (Groher, 1990):

$$
\chi_{i}^{w^{*}}=\chi_{i}^{\text {wedid }} \exp \left(\left(\Delta H_{f} / R T\right)\left(T_{m}-T\right) / T_{m}\right)
$$


where $\Delta H_{f}$ is the heat of fusion at the melting point and $T_{m}$ is the melting temperature. The interactions between organic solutes and organic liquids are often considered to be very near ideal, therefore $\gamma_{i}^{\text {NAPL }}$ may be assumed to be unity, and

$$
\chi_{\mathrm{PAH}}^{w}=\chi_{\mathrm{PAH}}^{\mathrm{NAPL}} \chi_{\mathrm{PAH}}^{w^{*}}
$$

Assuming that the density and molecular weight of the aqueous phase is unaffected by the PAH solutes, this relationship can be written as (Sitar et al., 1990; Feenstra, 1990):

$$
C_{\text {PAH }}^{w}=\chi_{\text {PAH }}^{N A{ }^{N}} C_{\text {PAH }}^{W *}
$$

where $C_{\mathrm{PAH}}^{\mathrm{w}^{\bullet}}$ is the pure liquid compound solubility in water.

Using this approach for naphthane $\left(\Delta \mathrm{H}_{\mathrm{f}}=-18,200 \mathrm{~J} / \mathrm{mole}, \mathrm{T}_{\mathrm{m}}=80^{\circ} \mathrm{C}\right.$ and pure solid solubility $=$ $31.7 \mathrm{mg} /$; Tsonopoulos and Prausnitz, 1971: Mackay and Shiu, 1977), and for the coal tar (2.16\% naphthalene, average coal tar molecular weight $=210 \mathrm{~g} /$ mole; Peters and Luthy, 1991), it is calculated that equilibrium naphthalene solubility from coal tar is about $3.5 \mathrm{mg} / \mathrm{L}$ at $25^{\circ} \mathrm{C}$. This agrees well with measured values of naphthalene solubility of 3 to $4 \mathrm{mg} /$ in batch systems with coal-tar-impregnated microporous sodium silicate.

This approach is one method which can be used to predict the change in equilibrium aqueous phase concentration of PAH solute during microbial degradation. Other models for equilibrium solubilization have recenuly been used for NAPL-water systems by utilizing a non-linear relationship for the aqueous phase concentration and NAPL mole fraction (Wise et al., 1991). Such relationships stem from thermodynamic equations of state. These predictions of equilibrium concentrations will also provide information on the concentration gradient driving force for mass transfer.

\section{Modeling Rate-Limited Mass Exchange of PAH from Cral Tar NAPL}

The driving force for mass transfer processes is the difference in concentrations, more specifically chemical potentials, between the bulk aqueous phase $\left(C_{i}\right)$ and that conceitration which would be in equilibrium with the organic phase $\left(\mathrm{C}_{i}^{\mathrm{eqm}}\right)$. The flux of a species $\left(\mathrm{J}^{\circ}\right)$ can then be written as this driving force times an overall mass transfer cocfficient (K) (Treybal, 1980): 


$$
j^{o}=K\left(C_{i}^{\text {capm }} \cdot C_{i}\right)
$$

The overall mass transfer coefficient incorporates resistances to mass transfer in both the aqueous and organic phases. For NAPL mixtures, the equilibrium concentration is given by equation 5 . The source of contamination in the vicinity of a NAPL can be expressed as the flux (equation 6) times the specific surface area (area per unit volume of medium) across which mass transfer can occur. Since in most NAPL contamination scenarios the specific surface area is unknown, a lumped mass transfer coefficient (Ka) is employed (Powers et al., in prep.(a)).

An expression for the aqueous phase concentration within a reactor can be derived from mass balance equations, neglecting dispersion. For the continuously stirred reactors used for control experiments, the transpon of a PAH compound in the aqueous phase can be written as:

$$
\theta^{w} \frac{\partial C_{P A H}}{\partial l}=-Q C_{P A H}+K a\left(\chi_{P A H}^{N A P L} C_{P A H}^{w^{*}}-C_{P A H}\right)
$$

where $C_{\mathrm{PAH}_{\mathrm{H}}}$ is the aqueous phase concentration, $\theta^{\mathrm{w}}$ is the volumetric fraction of the aqueous phase in the reactor, and $\mathrm{Q}$ is the aqueous phase flow rate. Similarly, transpor of a soluble PAH species in aqueous phase in a packed column can be writuen as:

$$
\theta^{w} \frac{\partial C_{\text {PAH }}}{\partial t}=-q \frac{\partial C_{\text {PAH }}}{\partial x}+K a\left(\chi_{P A H}^{N A P L} C_{P A H}^{w^{\bullet}}-C_{\text {PAH }}\right)
$$

where $q$ is the superficial velocity. The volumetric fraction of water and the mole fraction of the PAH compound in the NAPL change slowly with time as the mass of NAPL is depleted. A NAPL phase balance must also be written in order to solve either of these equations:

$$
\frac{\partial\left(\chi_{\mathrm{PAH}}^{\text {NAPL }} \Theta^{N A P L} \rho^{N A P L} M W^{\mathrm{PAH}} / M W^{N A P L}\right)}{\partial t}=-K a\left(\chi_{\mathrm{PAH}}^{\text {NAPL }} C_{\mathrm{PAH}}^{w^{*}}-C_{\mathrm{PAH}}\right)
$$

Here $\theta^{N A P L}$ is the NAPL volumetric fraction $\left(\theta^{w}+\theta^{N A P L}=n\right), n$ is the porosity, $\rho^{\text {NAPL }}$ is the NAPL density, $M W^{P A H}$ is the molecular weight of the PAH species of concem, and MWNAPL is the average molecular weight of the coa: tar phase. 
From a practical standpoint, since coal tar consists primarily of insoluble species, the vclumetric fractions, molecular weight and density of the NAPL will not change substantially. These coefficients can be considered to be constant during the time that a more soluble component is leaching from the NAPL. In addition, a psuedo-steady-state period can be defined during the initial stages of dissolution. Effluent aqueous phase concentrations have been found to remain essentially constant 'or several porevolumes of water pumped through the column, until a significant fraction of the source his been depleted (Powers et al., in prep.(b); Borden and Koa, 1989; Geller, 1990). During this period, lumped mass transfer coefficients for the continuously-stirred reactor can be calculated directly from equation 7 :

$$
K a=Q C_{\text {PAH }} /\left(\chi_{\text {PAH }}^{N A P L} C_{P A H}^{W^{*}}-C_{\text {PAH }}\right)
$$

Equation 8 can be solved for the lumped mass transfer coefficients for a packed column by incorporating a first lype boundary condition at the column inlet $(C=0$ at $x=0)$ :

$$
K a=\frac{q}{x} \operatorname{Ln}\left[1-\frac{C_{\text {PAH }}}{\chi_{\text {PAH }}^{\text {NAPL }} C_{\text {PAH }}^{\omega^{*}}}\right]
$$

Equations 10 and 11 will be utilized to calculate lumped mass transfer coefficients for the continuouslystirred and column reactors. Effluent aqueous phase concentrations and the initial mole fraction of a PAH species in the NAPL will need to be determined for these calculatious.

Analysis of long term experiments will require the simultaneous numerical solution of the nonlinear aqueous jinase transpon equation and NAPL phase balance. The numerical technique used to solve these equations will depend on the time-scale of the processes. In a similar analysis, Powers et al. (1991) utilized a finite difference scheme to approximate the time derivatives (equation 8). With this approacn, slowly changing coefficients could be lagged one time-step without loss of numerical integrity. Alternative numerical methods will be explored if it is observed that the aqueous phase concentration $J r$ PAH species mole fraction in the NAPL change more rapidly than this method would permit.

\section{Modeling Simultaneous So!ubilization and Biodegradation}

The following explains one technique that may be utilized to compare the rate of solute biomineralization with the rate of solute solubilization. Since the contents of the biometers are mixed intermittently, the mass transfer coefficient in the biometer batch reactors, $\mathrm{K}_{\mathrm{b}}$, corresponds to the minimum asymptotic value of the transfer coefficient, $\mathrm{Ka}$, determined from solubilization experiments 
using the continuously-stirred reactor at low fluid velocities. The aqueous concentration of PAH in the biometers can be represented by the following:

$$
\frac{\partial C_{P A H}}{\partial t}=K_{b}\left(C^{e q m}-C_{P A H}\right)-k C_{P A H}
$$

The first term on the right hand side is the increase in aqueous PAH concentration due to solubilization, while the second term represents the decrease in aqueous PAH concentration due to biodegra jation. In this example the kinetics of biodegradation is assumed to be first order with respect to PAH concentration, and $k$ is the pseudo-first-order biomineralization rate constant assuming zero growth of the acclimated cultures.

A analytical solution for the above equation, subject to the initial condition of zero PAH concentration in water prior to contacting with coal-tar media and inoculum, is:

$$
\operatorname{Ln}\left[\frac{C^{e q m}}{C^{e q m}-C_{\text {PAH }}\left(1+k / K_{b}\right)}\right]=\left(K_{b}+k\right) l
$$

When $k \gg K_{b}$, i.e., the rate constant for biomineralization is much greater than the solubilization mass transfer coefficient,

$$
C_{\text {PAH }}=C^{e q m}\left(K_{b} / k\right)\left(1-e^{-k t}\right)
$$

At large values of $\mathrm{kt}, \mathrm{C}_{\mathrm{PAH}}=\mathrm{Ceqm}^{\mathrm{eg}}\left(\mathrm{K}_{\mathrm{b}} \mathrm{k}\right)$, and the rate of biomineralization becomes

$$
\frac{\partial \mathrm{C}_{\mathrm{CO}_{2}}}{\partial \mathrm{l}}=\left.\cdot \frac{\partial \mathrm{C}_{\mathrm{PAH}}}{\partial \mathrm{t}}\right|_{\text {Biodegradation }}=k \mathrm{C}_{\mathrm{PAH}}=\mathrm{K}_{\mathrm{b}} \mathrm{C}^{\mathrm{eqm}}
$$

Thus, under conditions in which the PAH dissolves slowly into the aqueous phase, but is converted relatively rapidly to $\mathrm{CO}_{2}$, the overall rate of production of $\mathrm{CO}_{2}$ is similar to the rate of solubilization of $\mathrm{PAH}$. The above technique can therefore be used to test the hypothesis that the rate of solute 
solubilization limits the rate of solute biodegradation.

\section{Relevancy to Water Resources Problems}

Contamination of groundwater resources by organic solutes following the spill or leak of a NAPL is a problem of national concem. Even though many of these NAPL compounds are considered to be essentially insoluble, they are frequently found in the aqueous phase in concentratiois greater than the allowable drinking water quality standards (Feenstra and Cobum, 1986). Bioremediation has recently been proposed as one technique for managing wastes in the subsurface that results in destruction of the contaminants. While numerous investigators have explored the type of microorganism and nutrient requirements for sustaining a biorestoration effort (e.g., Madsen, 1991), little attention has been focused on understanding the physical and chemical phenomena in the subsurface that may hinder or facilitate remediation when coupled with biodegradation. Research efforts under this proposal aim to provide an understanding of "bioavailability" and its relation to rates and end points during microbial remediation. By measuring rates of solubilizstion and biomineralization, the hypothesis can be tested that the primary limiting factor in bioremediation is rates of solubilization not biokinetics. Understanding potential iimiting factors in remediation efforts will lead to better predictions of the efficiency of these techniques and may provide the basis for development of innovative aquifer remediation schemes. 


\section{References}

Alvarez, L.M., P.L. McCarty and P.V. Roberts, "The Effect of Sorption onto Soil/Sediment on Microbial Degradation of Organic Solutes", 1989, Abstract of paper presented at the 62 nd Annual WPCF Conference San Francisco, Calif., Oct. 15-19.

Borden, R.C. and C.M.Kao, "Water Flushing of Trapped Residual Hydrocartons: Mathematical Model Development and Laboratory Validation", 1989, paper presented at the NWWA Conference on Petroleum Hydrocarbons and Organic Chemicals in Ground Water, Houston, Texas, November $15 \cdot 17$.

Campbell, J.R. and R.G. Luthy, "Prediction of Aromatic Solute Partition Coefficients using the UNIFAC Group Contribution Model", 1985, Environ. Sci. Technol., 19(10), 980-985.

Dzombak, D.A. and R.G. Luthy, "Estimating Adsorption of Polycyclic Aromatic Hydrocarbons on Soils", 1984, Soil Science, 137, 292-308.

Edwards, D.A., Z. Liu and R.G. Luthy, "Nonionic Surfactant Solubilization of Hydrophobic Organic Compounds in Soil/Aqueous Systems", submitted to J. Environ. Eng., November, 1991.

Ertwards, D.A., Z. Liu and R.G. Luthy, "Experimental Data and Mudel Results for Nonionic-Surfactant Solubilization of Polycyclic Aromatic Hydrocarbons in Soil/Aqueous Systems", submitted to I. Environ. Eng., November, 1991.

Feenstra, S., "Evaluation of Multi-Coniponent DNAPL Sources by Monitoring of Dissolved-Phase Concentrations", 1990, paper presented at the Conference on Subsurface Contamination by Immiscible Fluids (International Association of Hydrology), Calgary, Alberta, April 18-20.

Feenstra, S. and J. Cobum, "Subsurface Contamination from Spills of Denser than Water Chlorinated Solvents", 1986, Califomia WPCA Bulletin, 23(4), 26“34.

Fried, J.J., P. Muntzer, and L. Zilliox, "Groundwter Pollution by Transfer of Oil-Hydrocarbons", 1979, Ground Wat., 17(6), 586-594.

Gauger, K., J.J. Kilbane, R.L. Kelley and V.J. Srivastava, "Enhancement of Microbial Degradation of Hydrocarbons in Soil and Water". 1989. Paper presented at Second International IGT Symposium on Gas, Oil, Coal and Ervironmental Biotechnology, New Orleans, LA, December 11-13.

Geller, J.T., "Dissolution of Non-Aqucous Phase Organic Liquids in Porous Media", 1990, PhD Disseration, University of Califomia, Berkeley, CA.

Groher, D.M., "An Investigation of Factors Affecting the Concentration of Polycyclic Aromatic Hydrocarbons in Groundwater at Coal Tar Waste Sites," 1990, M.S. Thesis in Environmental Science, Department of Civil Engincering, Massachusetts Institute of Technology, February.

Huling, S.G. and J.W. Weaver, "Dense Nonaqueous Phase Liquids", U.S. EPA, Office of Research and 
Development, EPA/540/4-91-002, March, 1991.

Karickhoff, W.W., "Organic Pollutant Sorption in Aquatic Systems," 1984, J. Hydraul. Eng., 110, 707-735.

Laha, S. and R.G. Luthy, "Inhibition of Phenanthrene Mineralization by Nonionic Surfactants in SoilWater Systems, 1991. Environ. Sci. Technol., 25(11), 1920-1930.

Lee, L.S. and P.S.C. Rao, "Processes Goveming the Partitioning of Organic Compounds at MGP Sites", 1991. paper presented at EPRI Technology Transfer Seminar or Marnagement of Manufactured Gas Plant Sites, Allanta, GA, April 2-3.

Mackay, D. and W.Y. Shiu, "Aqueous Solubility of Polynuclear Aromatic Hydracarbons", 1977, J. Chem. Eng. Data, 22(4), 399-402.

Madsen, E.L., "Determining In Situ Biodegradation", 1991, Environ. Sci. Technol, 25(10), 1662-1673.

Mihelcic, J.R. and R.G. Luthy, "Sorption and Microbial Degradation of Naphthalene in Soil Water Suspensions under Denitrification Conditions", 1990, Environ. Sci. Technol., 25, 169-177.

Miller, C.T., M.M. Poirier-MoNeill, and A.S. Mayer, "Dissolution of Trapped Nonaqueous Phase Liquids: Mass Transfer Characteristics", 1990. Water Resour. Res., 26(11), 2783-2796.

Nakles, D.V., D.G. Linz and I.P. Murarka, "Bioremediation of MGP Soils: Limitations and Potentials", 1991. Paper presented at EPRI Technology Transfer Seminar on Management of Manufactured Gas Plant Sites, Allanta, GA, April 2-3.

Neuhauser, E.F. personal communication, 1989. Niagara Mohawk Power Corporation, Syracuse, NY.

Ogram, A.V., R.E. Jessup, L.T. Ou, and P.S.C. Rao, "Effects of Sorption on Biological Degradation Rates of (2, 4-Dichlorophenoxy) acetic Acid in Soils, 1985. Appl. and Environ. Micmbiol., 49, 582-587.

Parker, J.C., A.K. Katyal, J.J. Kaluarachchi, R.J. Lenhard, T.J. Johnson, K. Jayaraman, K. Unlu, J.L. Zhu and P.K. Patel, "Modeling Multiphase Organic Chernical Transport in Soils and Groundwater", 1990, Final Report submilled to U.S. EPA-Project \#CR-814320.

Peters, C.A. and R.G. Luthy, "Coal Tar Dissolution in Water-Miscible Solvents", paper presented at the 64th Annual Conference, Water Poliution Control Federation, Toronto, Canada, October, 1991.

Powers, S.E., C.O. Loureiro, L.M. Abriola, and W.J. Weber, "Theoretical Study of the Significance of Nonequilibrium Dissolution of Nonaqueous Phase Liquids in Subsurface Systems", 1991, Water Resour. Res., 27(4), 463.477.

Powers, S.E., L.M. Abriola, and W.J. Weber, "An Experimental Investigation of NAPL Dissolution in Saturated Subsurface Systems: 1. Stear y-State Mass Transfer Rates", submitted to Water Resour. 
Res., November, 1991, (a).

Powers, S.E., L.M. Abriola, and W.J. Weber, "An Experimental Investigation of NAPL Dissolution in Saturated Subsurface Systems: 2. Transient Mass Transfer Rates", in preparation (b).

Razakarisoa, O., J.D. Rasolofoniaina, P. Muntzer and L. Zilliox, "Selective Dissolution and Transport of Hydrocarbons in an Alluvial Aquifer-Role and Impact of Residual Air on Ground Water Contamination", in Proceedings of the Intemational Symposium on Contaminant Transport in Ground water (April 4-6), edited by Kobus, H.E. and W. Kinzelbach, Stuttgart:1989.

Rijnaarts, H.H.M., A. Bachmann, J.C. Jumelet and A.J.B. Zehnder, "Effect of Desorption and Intraparticle Mass Transfer on the Aerobic Biomineralization of $\alpha$-Hexachlorocyclohexane in a Contaminated Calcareous Soil," 1990, Environ. Sci. Technol. 24, 1349-1354.

Sherman, D.F., R.C. Loehr and E.F. Neuhauser, "Development of Innovative Biological Techniques for the Bioremediation of Manufactured Gas Plant Sites," 1988, in Proceedings: International Conference on Physiochemical and Biological Detoxification of Hazardous Waste, Allantic City, N.J., May 3-5, Technomic Pub., Lancaster, Pa.

Sitar, N.. J.R. Hunt and J.T. Geller. "Practical Aspects of Multiphase Equilibria in Evaluating the Degree of Contamination", paper presented at the Conference on Subsurface Contamination by Immiscible Fluids (International Association of Hydrology; April 18-20), Calgary, Alberta, 1990.

Smith, J.R, and R.L. Weightman, "Co-Treatment of Manufactured Gas Plant Site Goundwaters with Municipal Wastewaters", 1988. Final Topical Kepor to the Gas Research Institute, Chicago, IL. Contract No. 5086-254-1350, August.

Smith, J.R., D.V. Nakles, M.A. Cushey, D.J. Morgan, and D. Linz, "Application of Biodegradation Screening Protocol to Contaminated Soil from a Manufactured Gas Plant Site", 1989, paper presented at Second Intemational IGT Symposium on Gas, Oil, Coal and Environmental Biotechnology, New Orleans, LA, December 11-13.

Smith, J.R., D.V. Nakjes, D.E. Sherman, E.F. Neuhauser, R.C. Loehr and D. Erickson, 1989, "Environmental Fate Mechanisms Influencing Biological Degradation of Coal-Tar Derived PAH in Soil Systems", paper presented at the Third International Conference on New Frontiers for Hazardous Waste Management, Piltsburgh, September 10-13.

Stucki, G. and M. Alexander. The Role of Dissolution Rate and Solubility in Biodegradation of Aromatic Compounds", 1987. Appl. Environ. Microbiol, 53, 292-297.

Thomas, J.M. and C.H. Ward, "In Situ Biorestoration of Organic Contaminants in the Subsurface", 1989. Environ. Sci. Technol., 23, 760-766.

Treybal, R.E., Mass Transfer Opcrations, 1980, 3rd Ed., McGraw-Hill, New York.

Tsonopoulos, C. and J.M. Prausnitz, "Activity Coefficients of Aromatic Solutes in Dilute Aqueous Solutions", 1971, Ind. Eng. Chem. Fundam., 10(4), 493-500. 
van der Waarden, M., A.L.A.M. Bridie, and W.M. Groenewoud, "Transport of Mineral Oil Components to Groundwater: (1) Model Experiments on the Transfer of Hydrocarbons from a Residual Oil Zone to Trickling Water", 1971, Water Res., 5, 213-226.

Villaume, J.F., "Investigations at Sites Contaminated with Dense, Non-Aqueous Phase Liquids (NAPLs)", 1985, Ground Water Monitoring Review, 5(2), 60-74.

Wise, W.R., G.C. Robinson and P.B. Bedient, "Contaminant Partitioning Between Residual Fuel and Groundwater", Groundwater, subrnitted July, 1991.

Wodzinski, R.S. and B. Bertolini, "Physical State in which Naphthalene and Biphenyl are Utilized by Bacteria", 1972, Appl. Microbiol., 27, 1077-1081.

Wodzinski, R.S. and J.E. Coyle, "Physical State of Phenanthrene for Utilization by Bacteria," 1974. Appl. Microbiol., 27, 1081-1084.

Yalkowsky, S.H., and S.C. Valvani, "Solubility and Partioning 2. Relationships Between Aqueous Solubilities, Partition Coefficients, and Molecular Surface Areas of Rigid Aromatic Hydrocartons", 1979, J. Chem. Eng. Data, 24(2), 127-129.

\section{DISCLAIMER}

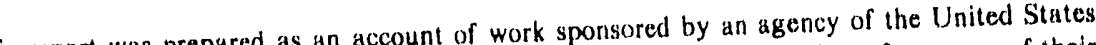
This report was prepared as an account of work sponernment nor any agency thereof, nor any of their Government. Neither the United States Government nor any agency legal liability or responsiemployees, makes any warranty, express or implied, or assumes any logal liability or responstbility for the accuracy, completeness, or usefulness of any information, apparaty owned rights. Referprocess disclosed, or represents that its use would not infringe privately owe trade name, Irademark, ence herein to any specific commercial product, process, or servico by trade name, irademark, manufacturer, or otherwise does not necessarily constitute or imply its endorsement, recommendation, or favoring by the United States Government or any agency therect those of the

and opinions of authors expressed herein do not 

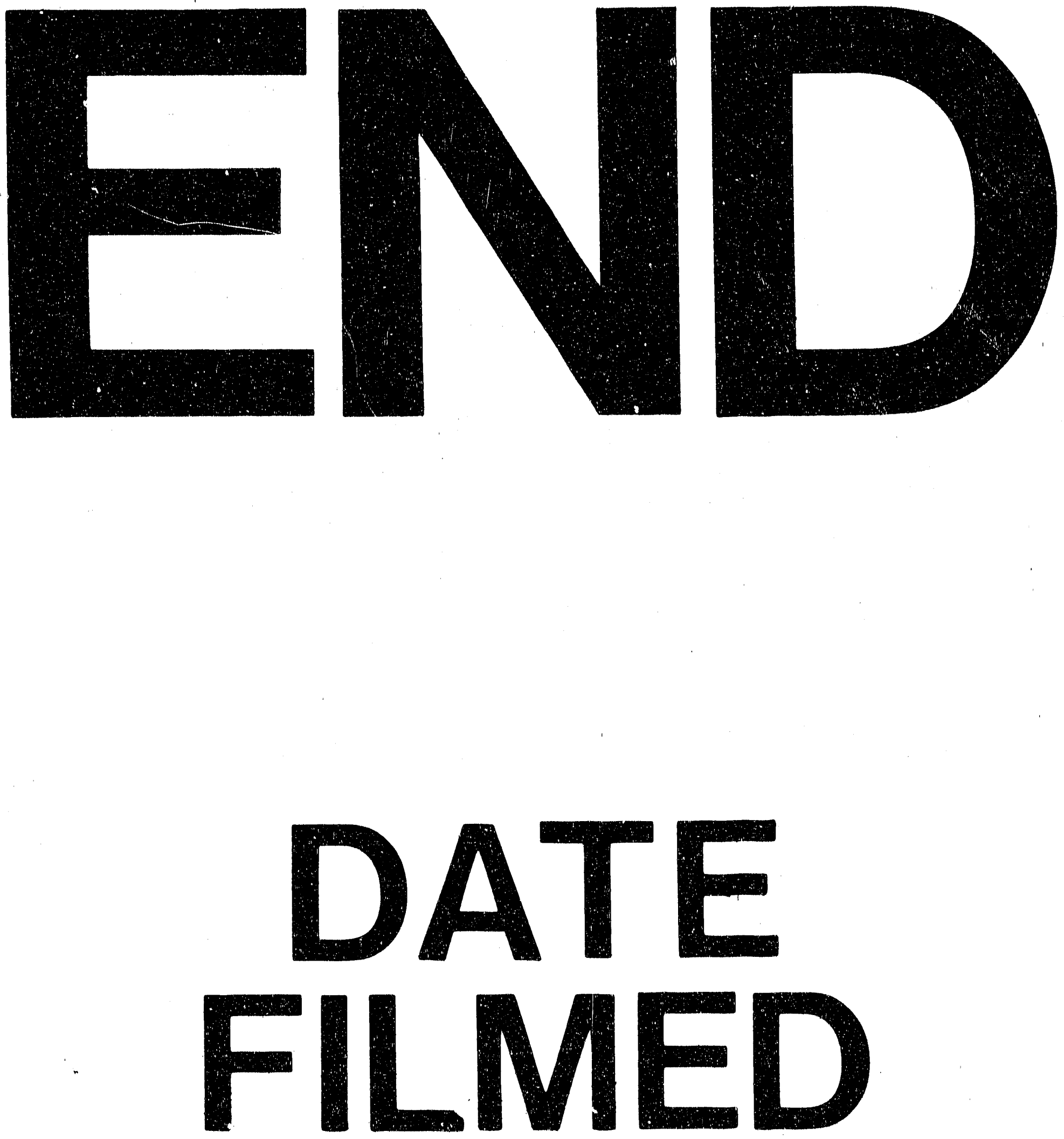

I

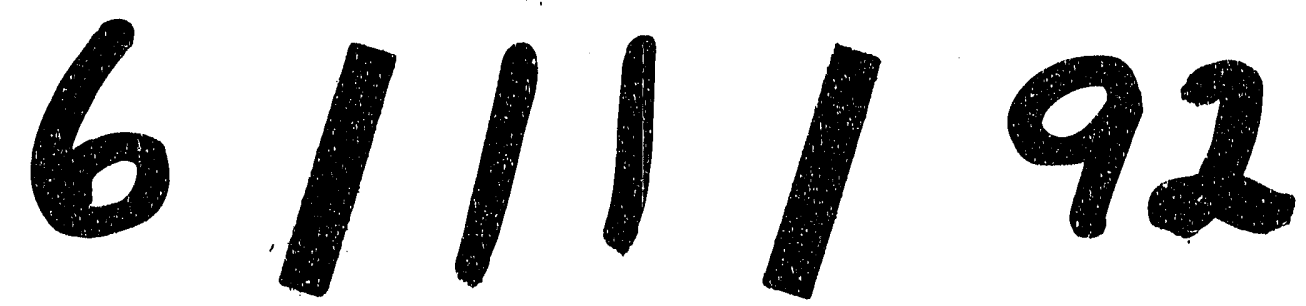


